\title{
EVALUASI PELAKSANAAN PROGRAM BANTUAN PERBAIKAN RUMAH UNTUK RUMAH TANGGA MISKIN (RTM) DI KOTA DENPASAR Wiwik Hermawati $^{1}$, I N. Sutarja ${ }^{2}$, dan Mayun Nadiasa ${ }^{2}$
}

\begin{abstract}
Abstrak : Upaya Pemerintah Kota Denpasar dalam mewujudkan kesejahteraan bagi masyarakat terutama rumah tangga miskin adalah melaksanakan program bantuan perbaikan rumah untuk Rumah Tangga Miskin (RTM) di Kota Denpasar untuk pemenuhan hak dasar akan rumah layak huni dan sehat. Dengan adanya berbagai permasalahan pada setiap pelaksanaan program pembangunan, maka penelitian ini bertujuan mengevaluasi pelaksanaan program yaitu untuk mengetahui tingkat efektivitas program serta hubungan antara efektivitas program dengan peningkatan kesejahteraan RTM.

Sumber data yang digunakan ada dua yaitu data primer yang diperoleh dari jawaban responden terhadap pertanyaan dalam kuesioner dan data sekunder yang di dapat dari Dinas Tata Ruang dan Perumahan Kota Denpasar serta instansi terkait. Metode pengumpulan data yang digunakan adalah wawancara dan kuisioner. Dari 30 butir pertanyaan pada kuesioner, semua dinyatakan valid dan reliable. Alat analisis yang digunakan adalah Analisis Deskritif, Analisis Efektivitas ditinjau dari variabel masukan/input, variabel keluaran/output, variabel hasil/outcome dan variabel dampak/impact dengan menggunakan modifikasi rumus Dantes, serta Analisis Chi Square untuk mengetahui hubungan antara efektivitas program dengan dampak program terhadap peningkatan kesejahteraan.

Dari lima katagori tingkat efektivitas berdasarkan rumus Dantes, hasil analisis jawaban dari 68 responden yang disebar di empat Kecamatan di Kota Denpasar, nilai skor total terhadap efektivitas pelaksanaan program didapat $X=4581$, berada dalam range $3400 \leq X \leq 4760$, menunjukkan bahwa pelaksanaan program bantuan perbaikan rumah untuk RTM di Kota Denpasar tergolong dalam katagori kurang efektif. Dengan nilai chi-square hasil penelitian adalah jauh lebih besar dari nilai chi-square kritik $(47,33>13,277)$ menunjukkan bahwa terdapat hubungan yang signifikan antara efektivitas program dengan dampak program terhadap peningkatan kesejahteraan masyarakat. Disarankan bila program bantuan ini akan dilanjutkan, agar dilakukan optimalisasi terhadap variable-variabel efektivitas serta perbaikan-perbaikan manajemen untuk peningkatan kesejahteraan masyarakat RTM. Kata Kunci : Evaluasi, Efektivitas, RTM, Program Bantuan Perbaikan Rumah
\end{abstract}

\section{THE EVALUATION OF RENOVATION AID PROGRAM IMPLEMENTATION FOR UNDERPRIVILEGED HOUSEHOLDS IN CITY OF DENPASAR}

Abstract : The endeavor of Denpasar City Government in establish the wellbeing of its people especially the underprivileged households is conducting a house renovation aid program in order to accomplish the essential privileges of livable and healthy housing. With numerous problems during the development program execution, therefore, this study is carried out to evaluate the program implementation to determine the program effectiveness index and its relationship between the program effectiveness and the increase of the wellbeing of underprivileged households.

The primary data are composed from survey feedbacks of sequence of questions in a questioner. While, the secondary data were collected from Office of Spatial Planning and Housing of the City of Denpasar and other related agencies. The methods used in data collection consist of interviews and questionnaires. Out of 30 questions in the questioner, all were affirmed valid and reliable. The analytical tool utilize in the study were descriptive analysis, effectiveness analysis in term of input variables, output variables, outcome variables and impact variables which modify Dantes' formula; and Chi Square analysis to distinguish the relationship between program effectiveness and program's impact to wellbeing improvement.

Of the five Dante's categories of effectiveness index, the analysis of the feedbacks of 68 respondents which distributed in four districts in the City of Denpasar are presented in this study. The total score value of program implementation effectiveness, indicated by $X, X=4581$, within the range $3400 \leq X \leq 4760$. This index value showed that the implementation of the house renovation for underprivileged households aid program is classified to be less effective. The value of Chi Square of the study is greater than its critical value $(47.33>13.277)$. It is indicating that there is a significant relationship between program effectiveness and the program impact to the people wellbeing improvement. It is suggested that when the program and its impact is to be continued, the effectiveness variables need to be optimized and so the managements improvements in order to increase the wellbeing of the underprivileged households.

Key Words: Evaluation, Effectiveness, Underprivileged Households, House Renovation Aid Program.

\footnotetext{
${ }^{1}$ Mahasiswa Program Studi Magister Teknik Sipil, Program Pascasarjana, Universitas Udayana, Denpasar

${ }^{2}$ Staf Pengajar Program Studi Magister Teknik Sipil, Program Pascasarjana, Universitas Udayana, Denpasar
} 


\section{PENDAHULUAN}

\section{Latar Belakang}

Undang-Undang Republik Indonesia Nomor 1 Tahun 2011 tentang Perumahan dan Kawasan Permukiman, yang menyebutkan bahwa setiap orang berhak hidup sejahtera lahir dan batin, bertempat tinggal, dan mendapatkan lingkungan hidup yang baik dan sehat, yang merupakan kebutuhan dasar manusia, dimana merupakan kewajiban Pemerintah sebagai penyelenggara negara untuk menghormati, melindungi dan sekaligus memenuhinya dengan segera.

Untuk mendukung pelaksanaan program-program pembangunan baik pusat maupun provinsi, Pemerintah Kota Denpasar menyusun Rencana Pembangunan Jangka Menengah Daerah (RPJMD) Kota Denpasar, untuk dijadikan sebagai pedoman, landasan, dalam menetapkan skala prioritas Rencana Kerja Pembangunan Daerah (RKPD) Kota Denpasar. Materi Visi, Misi dan Program Pembangunan Kota Denpasar tertuang dalam Peraturan Daerah Kota Denpasar Nomor 6 Tahun 2012 Tentang Rencana Pembangunan Jangka Menengah Daerah (RPJMD) Kota Denpasar Tahun 2010-2014, yang merupakan pengembangan dan penyempurnaan programprogram pembangunan sebelumnya.

Kota Denpasar, sebagai ibu kota Provinsi Bali yang menjadi tujuan urbanisasi dari berbagai daerah di sekitarnya bahkan dari luar pulau juga tidak terlepas dari persoalan penyediaan perumahan. Perkembangan penduduk di Kota Denpasar tiap tahunnya terus mengalami peningkatan yang berdampak pada kebutuhan perumahan penduduk beserta infrastruktur, sarana dan prasarana yang semakin meningkat pula. Kebutuhan ruangruang perumahan di Kota Denpasar semakin terbatas, terkait dengan ketersediaan lahan dan daya tampung wilayah yang telah melampaui batas pemanfaatan ruang yang ada.

Komitmen Pemerintah Kota Denpasar dalam memberikan perhatian kepada masyarakat berpenghasilan rendah (MBR) serta mewujudkan tujuan pembangunan Kota Denpasar dalam bidang perumahan, yaitu terciptanya pembangunan rumah layak huni bagi seluruh masyarakat Kota Denpasar, melalui Dinas Tata Ruang dan Perumahan diimplementasikan dengan melaksanakan Program Bantuan Perbaikan Rumah untuk Rumah Tangga Miskin (RTM).

Berdasarkan ketersediaan dana pada Anggaran Pendapatan dan Belanja Daerah (APBD) Kota Denpasar, dari Tahun Anggaran 2010 sampai Tahun Anggaran Induk 2013 telah direalisasikan 432 unit rumah. Bila dikaitkan dengan jumlah target unit rumah yang mendapatkan program bantuan, program ini dapat dikatakan capain kinerjanya baik, tetapi permasalahan yang dihadapi dalam pelaksanaan program bantuan perbaikan rumah ini adalah apakah program bantuan ini sudah mencapai sasaran yang tepat, yang dapat mampu memberikan manfaat penguatan bagi masyarakat untuk membangun daya yang dimiliki, untuk meningkatkan kapasitas masyarakat sasaran program sebagai sumber daya pembangunan menuju peningkatan kesejahteraan serta terpenuhinya hak dasar menempati rumah layak huni.

Dalam pelaksanaannya, program bantuan perbaikan rumah untuk RTM ini tidak terlepas dari beberapa permasalahan, seperti misalnya munculnya beberapa keluhan sejumlah masyarakat penerima bantuan sehubungan dengan kualitas material bangunan atau pelaksanaannya dimana beberapa unit rumah mengalami kebocoran atap ( Berita Bali, 2010 ); adanya penilaian masyarakat properti ( REI Bali ) bahwa implementasi program perbaikan rumah yang tidak layak huni tidak memiliki spesifikasi yang jelas dan tidak memiliki standar bangunan ( Baliterkini, 2011); adanya persoalan program bantuan terbentur masalah administrasi ( Berita Properti, 2013 ); adanya protes warga terkait ketidaksesuaian kriteria penerima bantuan ( Antara, 2013 ); adanya ketidakjelasan penggunaan dana bantuan ( Pos Bali, 2013 ), dan masih banyak persoalan yang terjadi di beberapa lokasi, baik yang terungkap media maupun tidak.

\section{Rumusan Masalah}

1. Bagaimana tingkat efektivitas pelaksanaan program bantuan perbaikan rumah untuk RTM di Kota Denpasar?

2. Bagaimana hubungan antara efektivitas pelaksanaan program bantuan perbaikan rumah untuk RTM di Kota Denpasar dengan dampak program terkait peningkatan kesejahteraan rumah tangga miskin di Kota Denpasar?

\section{Tujuan Penelitian}

1. Mengevaluasi tingkat efektivitas pelaksanaan program bantuan perbaikan rumah untuk RTM di Kota Denpasar.

2. Mengetahui hubungan antara efektivitas pelaksanaan program bantuan perbaikan rumah untuk RTM dengan dampak program terkait 
peningkatan kesejahteraan rumah tangga miskin di Kota Denpasar.

\section{TINJAUAN PUSTAKA}

\section{Evaluasi Program}

Usaha pencapaian tujuan program harus selalu diusahakan dalam suatu manajemen organisasi. Usaha tersebut dimulai dari penyusunan rencana strategis jangka panjang, jangka menengah, maupun jangka pendek, yang merupakan penetapan komitmen bersama semua unsur dalam organisasi untuk mewujudkan visi, misi dan tujuan organisasi yang dijabarkan dalam program-program kegiatan.

Berbagai program yang telah ada maupun yang akan dilaksanakan, memerlukan pemikiran baik dalam sistem perencanaan, pelaksanaan maupun evaluasinya. Keberhasilan suatu program dapat dilihat dari kesesuaian antara perencanaan dan pelaksanaannya, terukur hasilnya, serta adanya keberlanjutan kegiatan sebagai dampak program itu sendiri. Dari kegiatan evaluasi, keberhasilan, hambatan-hambatan maupun dampak suatu program dapat diketahui.

Untuk kegiatan-kegiatan atau program-program pemerintah, sistem evaluasi diatur dalam Peraturan Pemerintah Republik Indonesia Nomor 39 Tahun 2006 tentang Tata Cara Pengendalian dan Evaluasi Pelaksanaan Rencana Pembangunan, dimana disebutkan evaluasi adalah merupakan serangkaian kegiatan membandingkan realisasi masukan (input), keluaran (output), dan hasil (outcome) terhadap rencana dan standar.

\section{Efektivitas}

Kamus ilmiah populer mendefinisikan efektivitas sebagai ketepatan penggunaan, hasil guna atau menunjang tujuan. Efektivitas adalah ukuran yang menunjukkan seberapa jauh program/kegiatan mencapai hasil dan manfaat yang diharapkan.

Efektivitas mempunyai arti yang berbeda-beda bagi setiap orang, tergantung pada kerangka acuan yang dipakainya. Pengertian yang memadai mengenai tujuan efektivitas ataupun sasaran merupakan langkah pertama dalam pembahasan efektivitas, dimana hal ini sering kali berhubungan dengan tujuan yang ingin dicapai.

Dalam Sutrisno (2007), program atau usaha dikatakan efektif apabila suatu usaha mencapai tujuan yang diharapkan. Adapun untuk mengukur efektivitas suatu kegiatan/aktivitas perlu diperhatikan beberapa indikator, yaitu: (1) Pemahaman Program; (2) Tepat Sasaran; (3) Tepat Waktu; (4) Tercapainya Tujuan dan (5) Perubahan Nyata. Dalam Helyantina (2012) disebutkan bahwa efektivitas menurut Modifikasi Dantes (2001), adalah hubungan antara output dan tujuan atau dapat juga ikatakan merupakan ukuran seberapa jauh tingkat output, kebijakan dan prosedur dari organisasi. Efektivitas juga berhubungan dengan derajat keberhasilan suatu operasi pada sektor publik sehingga kegiatan dikatakan efektif jika kegiatan tersebut mempunyai pengaruh besar terhadap kemampuan penyediaan pelayanan.

\section{Kemiskinan}

Berbagai definisi, penyebab, serta indikator-indikator kemiskinan dinyatakan oleh beberapa ahli/peneliti atau lembaga penanganan kemiskinan, untuk menemukan berbagai program penanggulangan kemiskinan yang terintegrasi dan tidak tumpang tindih. Kemiskinan juga menjadi perhatian lembagalembaga internasional, seperti Bank Dunia, dimana menurut World Bank Institute (2005), ada empat alasan memberi perhatian terhadap kemiskinan. Pertama adalah untuk membuat orang miskin terus berada dalam agenda; agar orang miskin tidak terlupakan. Kedua, orang harus mampu mengidentifikasi orang miskin jika salah satu tujuannya adalah untuk keperluan intervensi dalam rangka mengentaskan kemiskinan. Ketiga adalah untuk memantau dan mengevaluasi proyek-proyek atau kebijakan intervensi yang diarahkan kepada orang miskin. Dan Keempat adalah untuk mengevaluasi efektivitas lembaga-lembaga pemerintah dalam mengentaskan kemiskinan.

\section{Program Bantuan Perbaikan Rumah untuk Rumah Tangga Miskin (RTM) di Kota Denpasar}

Program perbaikan rumah untuk rumah tangga miskin (RTM) di Kota Denpasar merupakan bantuan yang diberikan kepada masyarakat miskin yang menempati / mempunyai rumah tidak layak huni dengan tujuan dalam rangka meningkatkan kualitas hidup/derajat kesehatan masyarakat miskin.

Rumah tidak layak huni adalah suatu hunian atau tempat tinggal yang tidak layak dihuni karena tidak memenuhi persyaratan untuk hunian baik secara teknis maupun non teknis.

Program bantuan perbaikan rumah perlu mendapat perhatian khusus demi terciptanya kehidupan yang sejahtera. Kenyataannya, untuk mewujudkan rumah yang 
memenuhi persyaratan layak huni tersebut, bukanlah hal yang mudah. Ketidakberdayaan mereka untuk memenuhi kebutuhan rumah yang layak huni berbanding lurus dengan pendapatan dan pengetahuan tentang fungsi rumah itu sendiri.

Adapun yang menjadi sasaran program adalah rumah tangga miskin (RTM) yang tercantum dalam data base, sesuai dengan Surat Keputusan Walikota Denpasar. Untuk mewujudkan masyarakat miskin dapat menempati rumah layak huni/ sehat, dasar penetapan sasaran penerima bantuan perbaikan rumah untuk RTM di Kota Denpasar adalah Surat Keputusan Walikota Denpasar Nomor 188.45/605/HK/2011, tanggal 17 Oktober 2011 tentang Penetapan Data Base Kemiskinan Di Kota Denpasar Tahun 2011, dimana tercatat 2.586 Rumah Tangga Miskin di empat kecamatan di Kota Denpasar, Surat Keputusan Walikota Denpasar Nomor 188.45/798/HK/2012, tentang Penetapan Data Base Kemiskinan Di Kota Denpasar Tahun 2012, terdapat 2.106 Rumah Tangga Miskin, serta Surat Keputusan Walikota Denpasar Nomor 188.45/350/HK/2013, tentang Penetapan Data Base Kemiskinan Di Kota Denpasar Tahun 2013, terdapat 1.844 Rumah Tangga Miskin untuk mewujudkan masyarakat miskin dapat menempati rumah layak huni/ sehat.

\section{METODE PENELITIAN}

\section{Rancangan Penelitian}

Program Bantuan Perbaikan Rumah untuk Rumah Tangga Miskin (RTM) di Kota Denpasar merupakan salah satu program Pemerintah Kota Denpasar dalam upaya pemenuhan kebutuhan dasar akan rumah yang layak huni/sehat bagi masyarakat RTM Kota Denpasar. Untuk mengetahui keberhasilan pelaksanaan program akan dipergunakan evaluasi tingkat efektivitas program yang diukur melalui variabel masukan/input, variabel keluaran/output, variabel hasil/outcome serta variabel dampak/impact, sesuai dengan variabel-variabel yang tercantum dalam Peraturan Pemerintah Republik Indonesia Nomor 39 Tahun 2006 tentang Tata Cara Pengendalian dan Evaluasi Pelaksanaan Rencana Pembangunan. Efektivitas dari setiap variabel tersebut diharapkan mampu memberikan hasil sesuai tujuan program yaitu terpenuhinya kebutuhan rumah layak huni bagi RTM di Kota Denpasar serta dampaknya pada peningkatan kesejahteraan RTM, berupa peningkatan pendapatan serta peningkatan kesehatan.

\section{Lokasi dan Waktu Penelitian}

Adapun yang menjadi lokasi penelitian adalah Kota Denpasar dengan sebaran rumah tangga miskin (RTM) penerima program bantuan di empat Kecamatan, yaitu Kecamatan Denpasar Utara, Kecamatan Denpasar Timur, Kecamatan Denpasar Selatan dan Kecamatan Denpasar Barat, dengan ketersediaan dana pada APBD Kota Denpasar Tahun Anggaran 2012 dan Tahun Anggaran 2013 (induk).

\section{Jenis Data}

Dalam penelitian Evaluasi Pelaksanaan Program Bantuan Perbaikan Rumah untuk Rumah Tangga Miskin (RTM) di Kota Denpasar, jenis data yang digunakan adalah sebagai berikut :

1. Data Kuantitatif adalah data yang diperoleh dalam bentuk angka-angka, seperti misalnya data jumlah penduduk, jumlah penduduk miskin (RTM) penerima manfaat, besarnya bantuan yang diterima, dan lain-lain.

2. Data Kualitatif adalah data yang tidak berbentuk angka-angka yang diperoleh dari penelitian, misalnya data mengenai pendapat responden dari pertanyaan-pertanyaan yang diberikan dalam bentuk kuesioner.

\section{Variabel Penelitian}

Variabel - variabel dalam penelitian ini adalah sebagai berikut :

1. Variabel masukan/Input; dengan indikator : sosialisasi, ketepatan sasaran, ketepatan dana

2. Variabel Keluaran/output; dengan indikator : ketepatan jenis perbaikan, ketepatan bahan

3. Variabel Hasil/outcome; dengan indikator : tingkat kepuasan, tingkat kenyamanan dan keamanan

4. Variabel Dampak/impact; dengan indikator : tingkat kesehatan dan tingkat pendapatan

\section{Responden Penelitian}

Dalam penelitian ini, yang dimaksud dengan populasi adalah seluruh jumlah sasaran penerima Program Bantuan Perbaikan Rumah untuk RTM di Kota Denpasar Tahun Anggaran 2012, yaitu sebanyak 56 RTM dan Tahun Anggaran 2013 (induk) sebanyak 80 RTM yang tersebar di empat Kecamatan di Kota Denpasar, sehingga total populasi adalah 136 
RTM, atau lebih dari 100 maka ukuran sampel diharapkan sekurang-kurangnya 15 persen dari ukuran populasi. Penentuan jumlah sampel dapat dirumuskan sebagai berikut :

$$
\mathrm{S} \geq 15 \%+\frac{1000-\mathrm{n}}{1000-100} \quad(50 \%-15 \%)
$$

Dimana :

$\mathrm{S}$ = Jumlah sampel yang diambil

$\mathrm{n}=$ Jumlah populasi

Dengan jumlah populasi, $\mathrm{n}=136$, dengan mempergunakan rumus di atas, di dapat jumlah sampel (S) sekurang-kurangnya 66,096. Dalam penelitian ini, akan diambil sampel sebanyak 68 sampel yang akan didistribusi rata di empat Kecamatan, yaitu sebanyak 17 sampel yang dipakai sebagai responden pada tiap-tiap

\section{Pengujian Instrumen Penelitian}

Untuk menguji validitas alat ukur, terlebih dahulu dicari harga korelasi antara bagian-bagian dari alat ukur secara keseluruhan dengan cara mengkorelasikan setiap butir alat ukur dengan skor total yang merupakan jumlah tiap skor butir, menurut rumus Pearson Product Moment, sebagai berikut:

$$
\mathrm{r}=\frac{\mathrm{n}\left(\sum \mathrm{XY}\right)-\left(\sum \mathrm{X}\right)\left(\sum \mathrm{Y}\right)}{\sqrt{\left[\mathrm{n}\left(\sum \mathrm{X}^{2}\right)-\left(\sum \mathrm{X}\right)^{2}\right]\left[\mathrm{n}\left(\sum \mathrm{Y}^{2}\right)-\left(\sum \mathrm{Y}\right)^{2}\right]}}
$$

\section{Dimana:}

$$
\begin{array}{ll}
\mathrm{r}=\mathrm{r} \text { hitung } & =\text { koefisien korelasi } \\
\sum \mathrm{X} & =\text { jumlah skor item } \\
\sum \mathrm{Y} & =\underset{\text { jumlah skor total ( seluruh }}{\text { item })}
\end{array}
$$

Koefisien korelasi product moment dianggap valid jika lebih besar dari 0,3 atau bisa juga dengan membandingkan dengan $r$ tabel. Jika $r$ hitung > $r$ tabel maka dinyatakan valid.

Metode pengujian reliabilitas instrumen ini dapat dilakukan dengan berbagai cara antara lain: belah dua (split half) dari Spearman Brown, sebagai berikut: (Riduwan, 2010)

$$
\text { 2.rb }
$$

$$
\text { K } \mathrm{r} 11=: \frac{}{1+\mathrm{rb}}
$$

r11 adalah koefisien reliabilitas internal seluruh item

rb adalah korelasi Product Moment antara belahan dengan kaidah keputusan, bila $\mathrm{r} 11>\mathrm{r}$ tabel berarti reliable dan bila $\mathrm{r} 11<\mathrm{r}$ tabel berarti tidak reliable.

\section{Analisis Data}

1. Analisis Deskriptif

Menurut Sugiyono (2013), Statistik deskriptif dapat digunakan bila peneliti hanya ingin mendeskripsikan data sampel, dan tidak ingin membuat kesimpulan yang berlaku untuk populasi dimana sampel diambil.

2. Analisis Efektivitas

Menurut Rumus Dantes, dalam Helyantina (2012), perhitungan katagori efektivitas diukur berdasarkan jumlah skor total setiap variable yang diperoleh melalui hasil jawaban responden

Tabel 1

Tingkat Kualifikasi Efektivitas

Nilai Interval Tingkat Capaian

$(\mathrm{Mi}+2 \mathrm{Sdi}) \leq \mathrm{x} \leq(\mathrm{Mi}+3 \mathrm{Sdi}) \quad$ Sangat Efektif $(\mathrm{Mi}+1 \mathrm{Sdi}) \leq \mathrm{x} \leq(\mathrm{Mi}+2 \mathrm{Sdi}) \quad$ Efektif

(Mi - 1 Sdi $) \leq \mathrm{x} \leq(\mathrm{Mi}+1 \mathrm{Sdi}) \quad$ Cukup Efektif

(Mi - 2 Sdi) $\leq \mathrm{x} \leq(\mathrm{Mi}-1 \mathrm{Sdi}) \quad$ Kurang E fektif $($ Mi -3 Sdi $) \leq x \leq($ Mi -2 Sdi $)$ Tidak Efektif

Sumber : Modifikasi Dantes(2001) dalam
Helyantina (2012)

Dimana :

$\mathrm{Mi}=$ Mean ideal $=(1 / 2 \times($ Skor max.ideal + Skor min.ideal))

$\mathrm{Sdi}=$ Standar Deviasi ideal $=(1 / 6 \times)($ Skor max.ideal - Skor min.ideal))

Skor max. ideal $=5 \mathrm{x}$ jumlah item pertanyaan $\mathrm{x}$ jumlah responden

Skor min. ideal $=1 \mathrm{x}$ jumlah item pertanyaan $\mathrm{x}$ jumlah responden

3. Analisis Chi Square

Dalam Riduwan (2010), untuk mengetahui signifikansi pengaruh efektifitas program terhadap peningkatan kesejahteraan penerima program, maka digunakan analisis Chi Square $\left(\chi^{2}\right)$. Apabila distribusi $\chi^{2}$ $\mathrm{h}$ (chi square hasil perhitungan) lebih besar dari $\chi \mathrm{t}$ (chi square tabel) keputusan berada di daerah penolakan terhadap hipotesis nol (Ho ditolak) dan menerima $\mathrm{Ha}$, sehingga kesimpulannya sesuai dengan formulasi yang terdapat pada $\mathrm{Ha}$ artinya terdapat hubungan signifikan antara variabel tersebut.

$$
\mathrm{x}^{2}=\sum \frac{(f o-f e)^{2}}{f e}
$$




$$
\begin{aligned}
& \mathrm{x}^{2}=\text { Nilai chi-kuadrat } \\
& f_{0}=\text { frekuaensi yang diobservasi } \\
& \text { (frekuensi empiris) } \\
& f e=\begin{array}{l}
\text { frekuensi tang diharapkan } \\
\text { (frekuensi teoritis) }
\end{array}
\end{aligned}
$$

$$
f e=\frac{\left(\sum f k\right) x\left(\sum f b\right)}{\sum T}
$$

$f e=$ frekuensi yang diharapkan (frekuensi teoritis)

$$
\begin{aligned}
& \sum f k=\text { jumlah frekuensi pada kolom } \\
& \sum f b=\text { jumlah frekuensi pada baris } \\
& \sum T=\text { jumlah keseluruhan baris atau kolom }
\end{aligned}
$$

\section{HASIL DAN PEMBAHASAN}

\section{Hasil Uji Validitas dan Reliabilitas Instrumen Penelitian}

Hasil skoring/penilaian instrumen berupa kuesioner yang terdiri dari 30 butir pertanyaan, diberikan kepada 68 responden, dengan ketentuan rentang nilai dalam skala Likert $1-5$, yang selanjutnya data tersebut diolah dengan software Microsoft Excel, maka didapat output uji validitas, $r$ hitung $>r$ tabel (dengan signifikansi 5\%), serta nilai reliabilitas o,99806 > 0,7, maka semua butir-butir pertanyaan adalah valid dan reliable, sehingga dapat dinyatakan layak sebagai instrumen penelitian.

\section{Kondisi Kerusakan Rumah Responden serta Jenis Perbaikannya \\ Ketersediaan dana perbaikan dialokasikan sesuai kondisi lapangan, disesuaikan dengan jenis kerusakan bahkan ada yang dibangun baru karena kerusakan yang sangat parah. Jenis-jenis pekerjaan perbaikan yang diberikan kepada masyarakat RTM penerima program dituangkan dalam perjanjian kontrak pelaksanaan dengan pihak ketiga yang disusun dalam rencana anggaran biaya (RAB) yang meliputi : (1) pekerjaan tanah dan persiapan, (2) pekerjaan beton, (3) pekerjaan pasangan termasuk pekerjaan pasangan dinding dan lantai, (4) pekerjaan kap, atap dan plafond, (5) pekerjaan kusen dan daun pintu, (6) pekerjaan finishing serta (7) pekerjaan sanitasi.}

\section{Analisis Efektivitas Pelaksanaan Program}

Hasil perhitungan semua variabel di atas secara keseluruhan atau variabel total, yang meliputi variabel masukan/input, variabel keluaran/output, variabel hasil/outcome maupun variabel dampak/impact sesuai dengan nilai interval dengan tingkat capaian efektifitas seperti pada Tabel 1 diatas, didapat hasil sebagai berikut :

\section{A. Variabel Masukan/Input}

Dari perhitungan hasil total skor (X) butir-butir pertanyaan pada variabel input, yang terdiri dari 12 butir pertanyaan, dengan jumlah responden sebanyak 68 adalah sebesar 1896. Variabel input dengan jumlah skor 1896 termasuk katagori kurang efektif. Nilai total skor pada variabel input ini disumbang oleh nilai skor pada indikator sosialisasi dan ketepatan sasaran yang tergolong kurang efektif dan nilai skor pada indikator ketepatan dana yang masuk dalam katagori tingkat efektivitas cukup efektif.

\section{B. Variabel Keluaran/Output}

Dari perhitungan hasil total skor (X) butir-butir pertanyaan pada variabel output, yang terdiri dari empat butir pertanyaan, dengan jumlah responden sebanyak 68 adalah sebesar 670 . Variabel output dengan jumlah skor 670 termasuk katagori cukup efektif. Dari indikator ketepatan jenis pekerjaan perbaikan dan ketepatan bahan, masuk dalam katagori cukup efektif.

\section{Variabel Hasil/Outcome}

Dari perhitungan hasil total skor (X) butir-butir pertanyaan pada variabel outcome yang terdiri dari 10 butir pertanyaan, dengan jumlah responden sebanyak 68 adalah sebesar 1492. Variabel outcome dengan jumlah skor 1492 termasuk katagori kurang efektif. Katagori kurang efektif pada variabel outcome ini merupakan kombinasi nilai skor pada indikator tingkat kepuasan yang kurang efektif dan nilai skor pada indikator tingkat kenyamanan dan keamanan yang cukup efektif.

D. Variabel Dampak/Impact

Dari perhitungan hasil total skor (X) butir-butir pertanyaan pada variabel impact yang terdiri dari 4 butir pertanyaan, dengan jumlah responden sebanyak 68 adalah sebesar 523. Variabel impact dengan jumlah skor 523 termasuk katagori kurang efektif baik dihasilkan dari skor indikator 
tingkat kesehatan maupun indikator tingkat pendapatan.

E. Variabel Total Efektivitas Program Dari perhitungan hasil total skor (X) butir-butir pertanyaan pada variabel total yaitu 4581 dengan 30 butir pertanyaan dari 68 responden, dimana berada dalam rentang skor $3400 \leq \mathrm{X}$ $\leq 4760$, maka pelaksanaan program bantuan perbaikan rumah untuk Rumah Tangga Miskin (RTM) di Kota Denpasar tergolong dalam katagori kurang efektif. Hasil perhitungan selengkapnya dari keempat variabel evaluasi efektivitas program dapat dilihat pada Tabel 2 berikut ini :

Tabel 2

Nilai Skor Variabel Penelitian

\begin{tabular}{|l|c|l|}
\hline $\begin{array}{c}\text { Variabel } \\
\text { Nilai } \\
\text { Skor }(\mathbf{X})\end{array}$ & Range Skor Nilai & Katagori \\
\hline $\begin{array}{l}\text { Input } \\
\mathrm{X}=1896\end{array}$ & $1360 \leq \mathrm{X} \leq 1904$ & $\begin{array}{l}\text { Kurang } \\
\text { efektif }\end{array}$ \\
\hline $\begin{array}{l}\text { Output } \\
\mathrm{X}=670\end{array}$ & $634,67 \leq \mathrm{X} \leq 997,33$ & $\begin{array}{l}\text { Cukup } \\
\text { efektif }\end{array}$ \\
\hline $\begin{array}{l}\text { Outcome } \\
\mathrm{X}=1492\end{array}$ & $1133,33 \leq \mathrm{X} \leq 1586,67$ & $\begin{array}{l}\text { Kurang } \\
\text { efektif }\end{array}$ \\
\hline $\begin{array}{l}\text { Impact } \\
\mathrm{X}=523\end{array}$ & $453,33 \leq \mathrm{X} \leq 634,67$ & $\begin{array}{l}\text { Kurang } \\
\text { efektif }\end{array}$ \\
\hline $\begin{array}{l}\text { Total } \\
\mathrm{X}=4581\end{array}$ & $3400 \leq \mathrm{X} \leq 4760$ & $\begin{array}{l}\text { Kurang } \\
\text { efektif }\end{array}$ \\
\hline
\end{tabular}

\section{Hubungan Efektivitas Program dengan Dampak Program terkait Peningkatan Kesejahteraan Sasaran Program}

Setiap program penanggulangan kemiskinan selalu berharap adanya dampak peningkatan kesejahteraan bagi masyarakat miskin penerima bantuan, setidaknya mampu memenuhi kebutuhan dasarnya sehari-hari. Peningkatan kesejahteraan dapat berupa peningkatan pendapatan, peningkatan kesehatan, pendidikan, kesempatan kerja maupun peningkatan perilaku menuju peningkatan kualitas kehidupan yang bermartabat. Rendahnya tingkat pendapatan menyebabkan taraf hidup yang rendah. Rendahnya pendapatan ditambah rendahnya tingkat pendidikan dan keterampilan menyebabkan pula rendahnya tingkat produktivitas, sehingga kemampuan untuk pemenuhan kebutuhan akan hak-hak dasar maupun fasilitas atau sarana pembaharuan sebagai faktor penentu peningkatan kesejahteraan hidup juga menjadi rendah ( Todaro, 1994).

Sejauh mana hubungan kedua variabel ini, masih perlu pengujian lebih lanjut melalui analisis chi-square. Dari hasil analisis chi-square diperoleh nilai chi-square hubungan antara efektivitas pelaksanaan program bantuan dengan tingkat kesejahteraan keluarga penerima bantuan, yaitu : $\chi 2$ hitung $=47,33$. Sedangkan nilai chi-square kritik untuk taraf signifikan 0,01 dan derajat bebas $(\mathrm{k}-1) \mathrm{x}(\mathrm{b}-$ 1) $=4$, dari tabel distribusi chi-square di dapat $\chi 2=13,277$. Hal ini menjelaskan bahwa nilai chi-square hasil penelitian adalah jauh lebih besar dari nilai chi-square kritik (47,33 > 13,277), sehingga antara kedua variabel penelitian yakni antara efektivitas pelaksanaan program bantuan perbaikan rumah dengan peningkatan kesejahteraan keluarga penerima bantuan mempunyai hubungan yang sangat signifikan atau sangat meyakinkan pada taraf uji $1 \%$ atau taraf kepercayaan $99 \%$.

\section{SIMPULAN DAN SARAN}

\section{Simpulan}

Berdasarkan hasil-hasil analisis data yang telah dilakukan dalam penelitian Evaluasi Pelaksanaan Program Bantuan Perbaikan Rumah untuk Rumah Tangga Miskin (RTM) di Kota Denpasar, maka dapat disimpulkan bahwa :

1. Dari hasil analisis efektivitas program yang terdiri dari variabel masukan/input (katagori kurang efektif); variabel keluaran/output (katagori cukup efektif); variabel hasil/outcome (katagori kurang efektif) serta variabel dampak/impact (katagori kurang efektif), maka tingkat efektivitas pelaksanaan program, yaitu dengan nilai skor keseluruhan variabel atau variabel total $\mathrm{X}=4581$ yang berada dalam range $3400 \leq X \leq 4760$, tergolong dalam katagori kurang efektif.

2. Berdasarkan hasil analisis Chi Square terhadap hubungan variabel efektivitas pelaksanaan program dengan variabel dampak program terkait peningkatan kesejahteraan RTM menunjukkan hubungan yang sangat signifikan, dimana bahwa nilai chi-square hasil penelitian adalah jauh lebih besar dari nilai chi-square kritik $(47,33>13,277)$, serta berdasarkan analisis dimana 
pelaksanaan program tergolong dalam katagori kurang efektif, maka hal ini menunjukkan bahwa pelaksanaan program bantuan ini kurang efektif untuk meningkatkan kesejahteraan RTM ke tingkat yang lebih tinggi.

\section{Saran}

Untuk meningkatkan efektivitas pelaksanaan program bantuan ini, disarankan agar dilakukan perbaikan-perbaikan dalam manajemen perencanaan, pelaksanaan maupun pengendalian program, terutama perbaikan terhadap indikator-indikator yang masih tergolong dalam katagori kurang efektif, yaitu : 1. Pada indikator sosialisasi dan ketepatan sasaran (variabel masukan/input) : pelaksanaan sosialisasi tidak harus dilakukan pada saat program akan dijalankan, melainkan dapat dilaksanakan sebelum program berlangsung, sehingga memberikan waktu yang cukup kepada penerima program untuk memahami tujuan program, mekanisme maupun ketentuanketentuan lainnya. Pelaksanaannyapun dapat dilakukan dengan berbagai media informasi sesuai dengan kemampuan dan kesempatan yang dimiliki penerima program. Dari kegiatan sosialisasi inilah segala informasi termasuk persyaratan sebagai penerima program dapat diketahui masyarakat, sehingga ketepatan sasaran penerima program dapat tercapai.

2. Pada indikator tingkat kepuasan (variabel hasil/outcome) dan indikator tingkat kesehatan dan tingkat pendapatan (variabel dampak/impact) : tindakan perbaikan maupun peningkatan pengelolaan program diutamakan melibatkan pemberdayaan masyarakat, agar mereka tidak semata menjadi obyek bantuan saja, melainkan masyarakat tetap dapat meningkatkan kualitas diri berupa peningkatan kesejahteraan bila bantuan ditiadakan, sehingga dapat memberikan kepuasan pada diri ekonomi dan sosial.

\section{DAFTAR PUSTAKA}

Anonim. 2006. Peraturan Pemerintah No. 39 Tahun 2006 Tentang Tata Cara
Pengendalian dan Evaluasi

Pelaksanaan Rencana Pembangunan.

Anonim. 2011. Undang-Undang Republik Indonesia No. 1 Tahun 2011 Tentang

Perumahan dan Kawasan

Permukiman.

Anonim. 2011. Keputusan Walikota Denpasar Nomor 188.45/605/HK/2011 tentang Penetapan Data Base Kemiskinan Di Kota Denpasar Tahun 2011.

Anonim. 2012. Keputusan Walikota Denpasar Nomor 188.45/798/HK/2012 tentang Penetapan Data Base Kemiskinan Di Kota Denpasar Tahun 2012

Anonim. 2013. Keputusan Walikota Denpasar Nomor 188.45/350/HK/2013 tentang Penetapan Data Base Kemiskinan Di Kota Denpasar Tahun 2013

Antara. 2013. Warga Protes Program Bedah Rumah. Available from : URL : http://th.tieba.com/forum/create?kw= Warga Protes Program Bedah Rumah 07 Oktober 2013

Baliterkini. 2011. REI Bali: Program Bedah Rumah Tak Punya Spesifikasi dan Standar Bangunan. Available from: URL: http://baliterkini.wordpress.com /2011/04/07/rei-bali-program-bedahrumah-tak-punya-spesifikasi-danstandar-bangunan

Berita Bali. 2010. Bedah Rumah 2011, Pemkot Anggarkan 1,7 M. Available from:URL:http://www.baidu.co.th/s? wd=Bedah Rumah 2011\%2C Pemkot Anggarkan 1\%2C7 M Jumat\%2C 31 Desember 2010

Berita Properti. 2013. Waduh, Program Bedah Rumah Rakyat Terbentur Masalah Administrasi dan Korupsi!. Available from:URL:http://www.baidu.co.th/s? $\underline{\text { wd=Waduh Program Bedah Rumah }}$ Rakyat Terbentur Masalah Administrasi dan Korupsi! 22 January 201 Berita Properti.

Helyantina, M. 2012. "Kajian Efektivitas Implementasi Perda No. 02/PD/DPRD/1972 Tentang Irigasi Di Daerah Provinsi Bali" (tesis).Denpasar : Universitas Udayana

Pos Bali, 2013. Dana Bedah Rumah Dipotong dan Dibagi-bagi Aparat Desa. Availablefrom:URL:http://www.baid u.co.th/s?wd=Dana Bedah Rumah Dipotong dan Dibagi-bagi Aparat Desa 27 Dec 2013 Pos Bali 
Riduwan. 2010. Metode dan Teknik Menyusun Tesis. Cetakan Kedelapan. Bandung: Alfabeta

Sugiyono. 2013. Metode Penelitian Bisnis. Cetakan ke-17. Bandung: Alfabeta.

Sutrisno, E .2007. Budaya Organisasi. Kencana. Jakarta.

Todaro, MP. 1994. Pembangunan Ekonomi 1. Edisi ke lima (Penerjemah Haris Munandar). P.T. Bumi Aksara. Jakarta.

World Bank Institute. 2005. Introduction to Poverty Analysis: Poverty Manual. World Bank Institute. 